\title{
Liver Transplantation in Malignancies: A Comprehensive and Systematic Review on Oncological Outcome
}

\author{
Emina Talakića, $^{b} \quad$ Elmar Janek $^{\mathrm{a}, \mathrm{b}}$ Saulius Mikalauskas ${ }^{\mathrm{b}, \mathrm{c}}$ Peter Schemmer $^{\mathrm{b}, \mathrm{c}}$ \\ ${ }^{a}$ Division of General Radiology, Department of Radiology, Medical University Graz (MUG), Graz, Austria; ${ }^{b}$ Transplant \\ Center Graz, Medical University Graz (MUG), Graz, Austria; ' General, Visceral and Transplant Surgery, Department of \\ Surgery, Medical University Graz (MUG), Graz, Austria
}

\section{Keywords}

Imaging · Indication for liver transplantation .

Liver malignancies · Liver transplantation · Survival

\begin{abstract}
Introduction: Liver transplantation (LT) is today's standard treatment for both end-stage liver disease and tumors; however, suitable grafts for LT are a scarce resource and outcome after LT is highly dependent on its underlying indication. Thus, patients must be carefully selected to optimize the number of life years gained per graft. This comprehensive and systematic review critically reflects the most recently published oncological outcome data after LT in malignancies based on the preoperative radiological findings. Methods: A systematic literature search was conducted to detect preferentially most recent high-volume series or large database analysis on oncological outcomes after LT for both primary liver cancer and liver metastases between January 1, 2019, and November 14, 2020. A comprehensive review on the radiological assessment of the reviewed liver malignancies is included and its preoperative value for an outcomedriven indication reflected. Results: Twenty most recent high-volume or relevant studies including a total number of 2,521 patients were identified including 4, 4, 4, 4, 3, and 1 publications on oncological outcome after LT for hepatocellular carcinoma, cholangiocellular carcinoma, hepatic epitheloid hemangioendothelioma, hepatoblastoma, and both metastatic neuroendocrine tumors and colorectal cancer, respectively. The overall survival is comparable to patients
\end{abstract}

without tumors if patients with malignancies are well selected for LT; however, this is highly dependent on tumor entity, tumor stage, and both neoadjuvant and concomitant treatment. Discussion/Conclusion: LT is a promising option for better survival in patients with malignant liver tumors in selected patients; however, the indication must be critically discussed prior to LT in every single case in the context of organ shortage.

(c) 2021 The Author(s)

Published by S. Karger AG, Basel

\section{Introduction}

Liver transplantation (LT) was especially designed as a complex procedure to treat liver malignancies. At the beginning of the LT era, Thomas E. Starzl pioneered this concept and has proven its feasibility in 2 consecutive patients who underwent LT in 1963 for hepatocellular carcinoma (HCC) and cholangiocellular carcinoma (CCC) with a survival of 22 and 7.5 days, respectively [1]. However, it was not before 1967 when he achieved 1-year survival after LT in a 19-month-old HCC patient [2]. According to the European LT Registry (ELTR), in the past, cancers constituted almost half of all the indications [3, 4].

LT has evolved over the last many years to a routine operation for well-defined standard indications. The underlying indications, however, have changed over the years due to a significantly better 5 -year patient survival after LT of $71 \%$ for cirrhosis as compared with $64 \%$ in
(C) 2021 The Author(s)

Published by S. Karger AG, Basel

This is an Open Access article licensed under the Creative Common Attribution-NonCommercial-4.0 International License (CC BY-NC) (http://www.karger.com/Services/OpenAccessLicense), applicable to the online version of the article only. Usage and distribution for commercial purposes requires written permission. 
primary liver tumors. Best survival was achieved after LT for congenital biliary (85\%), metabolic (79\%), and cholestatic (79\%) diseases [5]. Despite inferior survival rates, the incidence of LT for malignancies has doubled within the last decade to $>24 \%$ [5]. How can this be explained? During the last decade, the most important gain in survival was observed in patients who underwent LT for primary liver tumors and liver metastases with a 5-year survival of 67 and $61 \%$, respectively.

Advances in immunosuppressive regimens [6] and novel concepts in multimodal tumor therapy including innovative chemotherapeutic agents [7] justify evaluating novel protocols for the treatment of liver malignancies including LT in selected patients. However, clinical trials are needed to satisfy the demand for clinical evidence to implement both new prognostic markers and tailored therapy in cancer patients for better selection on an individual basis. Once new prognostic markers and anticancer regimens are implemented in the clinical selection and decision-making process, they need to be discussed on an individual basis in combined multidisciplinary transplant and tumor boards.

Thus, today LT is recommended based on both (inter) national guidelines and current publications for HCC, CCC, hepatic epitheloid hemangioendothelioma (HEHE), hepatoblastoma, and both metastatic neuroendocrine (NELM) and colorectal tumors [8-21] if specific criteria for the various tumors are fulfilled [3, 22]; however, especially in the latter 2 tumor entities, LT is only indicated in highly selected cases. Further, for CCC and for metastases of colorectal tumors, LT can only be recommended under controlled conditions like trials [3]. Thus, there are recruiting clinical trials to further develop the concept of LT in patients with cancer [23] aiming for novel concepts to improve survival [24] or to further expand the indications in selected tumor entities [25].

This comprehensive and systematic review critically reflects predictors for inferior oncological outcome, which are a prerequisite in the decision-making process on whether there is an indication for LT based on both tumor identification and staging [26, 27]. Further oncological outcome after LT for cancers is systematically presented and analyzed based on most current evidence, that is, observational data coming from databases, large cohorts, and randomized controlled trials.

\section{Methods}

Comprehensive Literature Search

To elucidate the indication for LT in liver malignancies including both the specific imaging patterns for the underlying tumor entity and prognostic factors, a literature search was conducted in the PubMed database with the following search terms: indications for outcome and/OR survival in liver transplantation in unresect- able malignancies OR outcome in liver transplantation for malignancies beyond hepatocellular carcinoma OR outcome in liver transplantation for HCC, CCC, hepatic epitheloid hemangioendothelioma, hepatoblastoma, and both metastatic neuroendocrine and colorectal tumors, respectively. Additionally for the specific imaging findings, we used the following terms: imaging of OR radiological findings of OR radiological assessment OR imaging patterns of HCC, CCC, hepatic epitheloid hemangioendothelioma, hepatoblastoma, both metastatic neuroendocrine and colorectal tumors, respectively. Result of the search was limited to clinical data only.

\section{Systematic Literature Search}

A systematic oncological outcome-based literature search in PubMed for reports published between January 1, 2019, and November 14, 2020, on patients who underwent LT for malignancies (HCC, CCC, HEHE, hepatoblastoma, and both NELM and colorectal tumors) was performed. This 2-year period was carefully selected to have the most recent state-of-the-art publications on oncological outcome in all the addressed tumor entities as a basis for new treatment strategies. The structured search strategy comprises the following search terms or a combination of them: outcome and/OR survival for LT in hepatocellular carcinoma OR HCC OR cholangiocarcinoma OR CCC, hepatic epitheloid hemangioendothelioma, hepatoblastoma, and both metastatic neuroendocrine and colorectal tumors, respectively. Only full-text articles published in English were assessed. Publications not based on observational data obtained from databases, large cohorts, and randomized controlled trials were excluded from the search results; however, authors' driven selection of all other studies based on novel information in the field of LT in malignancies or confirmatory data of today's standards was composed together in tables. Thus, there is one table per reviewed tumor entity. Results of the search were limited to clinical data only.

\section{Results}

\section{General Results of the Systematic Literature Search}

Twenty most recent high-volume studies including a total number of 2,521 patients were identified including $4,4,4,4,4,3$, and 1 publications on oncological outcome after LT for HCC, peripheral and intrahepatic CCC (pCCC, iCCC), HEHE, hepatoblastoma, and both NELM and colorectal tumors, respectively. If modern selection criteria are applied, an overall survival (OS) comparable to patients without tumors can be achieved after LT; however, both the selection criteria and the concomitant treatment including downstaging and/or perioperative chemotherapy are highly dependent on the tumor entity and stage. Most of the current evidence is based on observational data obtained from databases and other large cohorts retrospectively analyzed.

\section{Hepatocellular Carcinoma}

\section{Radiological Diagnosis}

During the hepatocarcinogenesis of HCC, several key changes happen such as progressive accumulation of an increased number of impaired arteries and a decreased 
number of portal tracts. These microvascular changes translate into the characteristic enhancing pattern of HCC marked as arterial phase hyperenhancement and washout on portal venous and/or delayed phases compared to the background liver on contrast-enhanced multiphasic computed tomography (CT) and magnetic resonance imaging (MRI). As in any solid tumors, HCC shows different and variable imaging features due to a wide spectrum of pathological and biological characteristics. Since none of these features taken separately is specific enough, a diagnosis of HCC is based on a combination of all of them [18].

\section{Radiological Predictors of Inferior Oncological Outcome}

Many staging systems and scores include parameters like size in diameter, total volume, and number of tumors in the liver [28-30]. With the increase of tumor size in diameter, the total tumor mass, and number of tumors, there is a decreased tumor-free survival after LT. This has been nicely demonstrated in the past [31,32]. Further, Otto et al. [33] demonstrated in 96 patients, with 62 patients outside the Milan criteria, that repeated TACE can successfully downstage HCC for LT. Today's tumor-associated contraindications for LT in the Western world include portal venous tumor thrombosis, cT4, and metastatic disease [34-36]. As international consensus recommends, imaging follow-up within 2 years after LT is very important due to usually recurrence of HCC at this time [30]. However, further studies suggest that systematic whole-body cross-sectional imaging follow-up should be performed even beyond 2 years after LT, since the delayed recurrence 2 years after LT is possible [37].

\section{Oncological Outcome Data}

In the most recent publications, the best tumor-free 2-year survival was achieved in patients who underwent LT for HCC within the Milan criteria. The recurrence rate (RR) in the cohort comprising 589 patients published by Al-Ameri et al. [38] was $8.9 \%$ within 2 years; however, in patients within the AFP model or within the Hangzhou criteria, the RR is higher with 11.8 and $15.8 \%$, respectively. The best 5 -year tumor-free survival was achieved in a total of 965 analyzed patients if they were within the 5-5-500 rule or within the Milan criteria with a low RR of only 7.3 and $7.5 \%$, respectively [19]. Patients within Milan or 5-5-500 still have shown a low RR of 9.1\% after 5 years [55]. Further, Shimamura et al. [19] demonstrated that patients within Milan and an AFP cut-off value of $500 \mathrm{ng} / \mathrm{mL}$ are at high risk, and thus, the 5-5-500 rule can expand the LT criteria for patients beyond Milan (Table 1). Meischl et al. analyzed their patients based on the histological explant Milan criteria and have not seen any different OS between their Milan and beyond Milan patients (Table 1). Interestingly, patients with a CRP of $\geq 1 \mathrm{mg} / \mathrm{mL}$ independent of Milan were associated with an inferior oncological outcome [17]. A cumulative HCC recurrence risk according to a novel oncological risk score (ORS) including AFP, CRP, and ALBI grade was demonstrated $[15,39]$. Thus, ALBI grade seems to be of value for better preoperative oncological risk stratification to calculate the novel ORS.

\section{Cholangiocellular Carcinoma}

Radiological Diagnosis

A combination of different imaging modalities in establishing the correct diagnosis has been demonstrated to be useful. Their choice depends on both tumor location and type. Multiphasic contrast-enhanced multidetector $\mathrm{CT}$ is the standard imaging method. The pre-contrast phase is useful in the detection of intraductal stones and in differentiating stones from pCCC. Post-contrast imaging includes arterial and portal venous phases and 3-5 min after contrast medium application, the delayed phase because iCCC shows an enhancement in the delayed phase due to its abundant fibrous stroma and also typical capsule retraction [10]. MRI in combination with MR cholangiopancreatography (MRCP) is a problem-solving tool in the differential diagnosis of CCC, in additional to CT. MRCP is very suitable for the assessment of pCCC. Endoscopic retrograde cholangiography (ERC) is capable for histological confirmation or biliary drainage in pCCC. For tumor staging in patients with potentially disease on $\mathrm{CT}$ and/or MRI, ${ }^{18} \mathrm{~F}$-FDG PET is appropriate [12]. Imaging features of a rare mixed HCC-iCCC tumor show a combined spectrum of iCCC and HCC. On further arterial enhancement with washout, a lobulated shaped lesion with hepatic capsular retraction and infiltration of the biliary tree is seen [40].

\section{Radiological Predictors of Inferior Oncological \\ Outcome}

The vascular invasion of CCC, tumor growth into the segmental bile ducts, and lymph node metastases are important factors for post-LT outcome. An accurate assessment for tumor extent with an appropriate imaging modality is of high importance in LT planning. CT is the imaging modality with a good sensitivity and specificity not only for the assessment of the vessels, tumor extent, and extrahepatic metastases in planning an LT but also for the assessment of possible anatomical vessel variants to reduce the possible complications in LT and eventually of outcome [41, 42]. Contrast-enhanced MRCP with gadolinium ethoxy benzylic diethylenetriamine pentaacetic acid (Gd-EOB-DTPA) is well suited for assessing the biliary system [43], both before and after LT. Further studies are needed to determine the imaging characteristics that predict outcome after LT. Nevertheless, LT is 
Table 1. Outcomes after LT for HCC

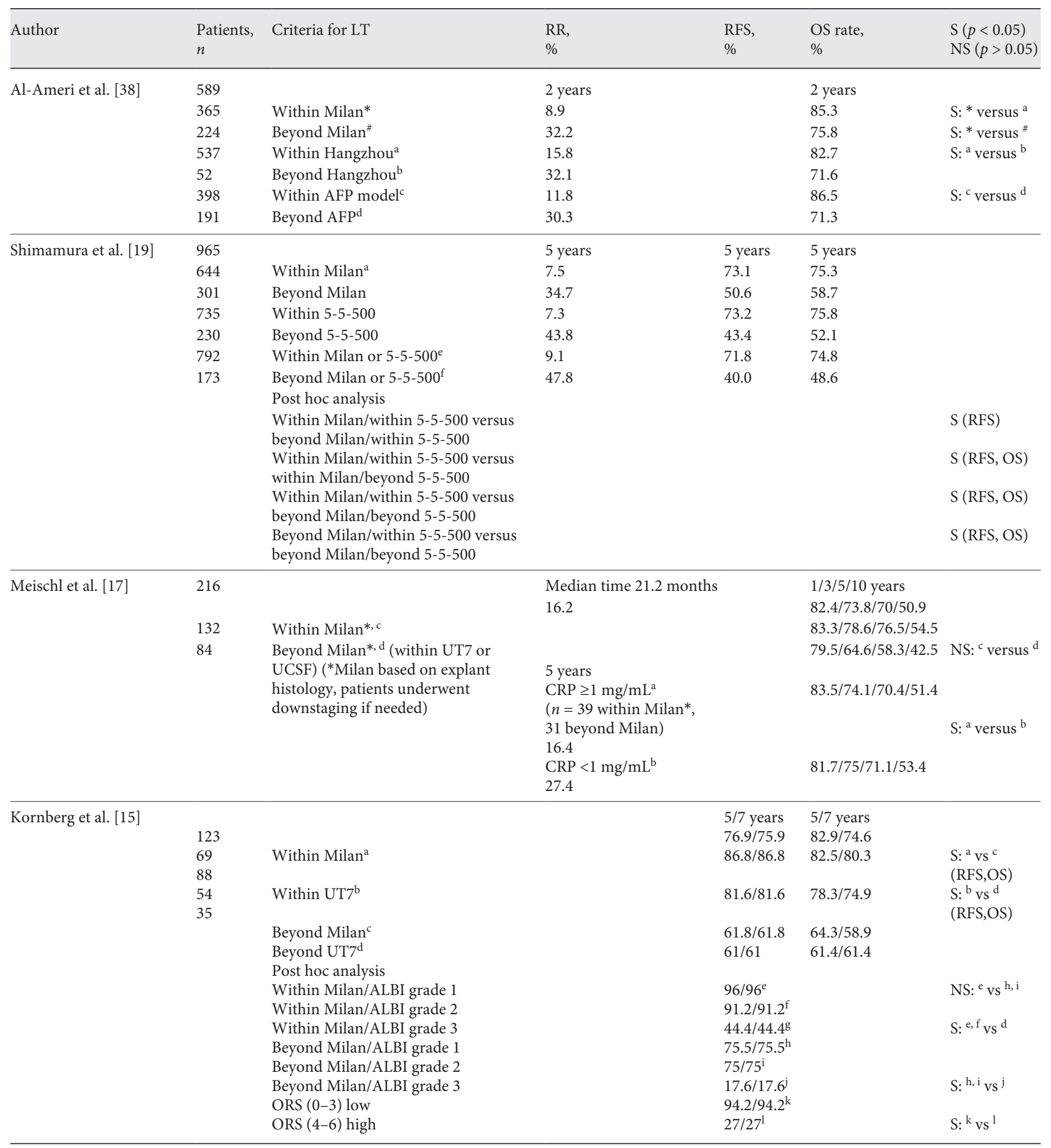

LT, liver transplantation; HCC, hepatocellular carcinoma; RR, recurrence rate; RFS, recurrence-free survival; OS, overall survival.

thought to have worse outcome in advanced CCC, as this is also observed for HCC. In general, however, postoperative complications such as vascular occlusion, aneurysm, bile leakage, anastomotic stenosis, and various fluid collections play a major role with regard to outcome after LT for CCC, most of which are related to neoadjuvant radio-chemotherapy. Therefore, patients should be closely followed up with imaging especially after LT for CCC [44]. 
Table 2. Outcomes after LT for CCC

\begin{tabular}{|c|c|c|c|c|c|c|}
\hline Author & $\begin{array}{l}\text { Patients, } \\
n\end{array}$ & Criteria for LT & $\begin{array}{l}\mathrm{RR}, \\
\%\end{array}$ & $\begin{array}{l}\text { RFS, } \\
\%\end{array}$ & $\begin{array}{l}\text { OS rate, } \\
\%\end{array}$ & $\begin{array}{l}\mathrm{S}(p<0.05) \\
\text { NS }(p>0.05)\end{array}$ \\
\hline Wong et al. [48] & 5 & $\begin{array}{l}\text { pCCC (LT after downstaging of locally } \\
\text { advanced pCCC) }\end{array}$ & & $\begin{array}{l}1 \text { year } \\
75\end{array}$ & $\begin{array}{l}1 \text { year } \\
80\end{array}$ & \\
\hline \multirow[t]{6}{*}{ Tan et al. [46] } & 74 & $\mathrm{pCCC}$ & 5 years & & $1 / 3 / 5 / 10$ years & \\
\hline & 25 & pCCC in non-PSC & $\begin{array}{l}12.3 \\
12.5\end{array}$ & & $\begin{array}{l}84.9 / 69.9 / 66.5 / 55.6 \\
1 / 3 / 5 / 10 \text { years }^{\mathrm{a}} \\
75 / 58 / 47.5 / 35.2\end{array}$ & $S:{ }^{a}$ versus $^{b}$ \\
\hline & 49 & pCCC in PSC & 12.2 & & $\begin{array}{l}1 / 3 / 5 / 10 \text { years }^{\text {b }} \\
89.8 / 75.9 / 75.9 / 73.2\end{array}$ & \\
\hline & & Post hoc analysis & & & & \\
\hline & & Residual tumor in pCCC in non-PSC & & & $\begin{array}{l}1 / 3 / 5 / 10 \text { years }^{c} \\
73.7 / 52.1 / 44.7 / 27.9\end{array}$ & $\begin{array}{l}S:{ }^{c} \text { versus }^{\mathrm{a}, \mathrm{b}} \\
\text { NS: }{ }^{\mathrm{c}} \text { versus }^{\mathrm{d}}\end{array}$ \\
\hline & & Residual tumor in pCCC in PSC & & & $\begin{array}{l}1 / 3 / 5 / 10 \text { years }^{\mathrm{d}} \\
81.3 / 45.1 / 45.1 / 36.1\end{array}$ & $S:{ }^{d}$ versus ${ }^{a, b}$ \\
\hline Krasnodębski et al. [45] & 10 & PSC with pCCC incidentaloma & & $\begin{array}{l}1 / 3 / 5 \text { years } \\
60 / 22.5 / 22.5\end{array}$ & & \\
\hline \multirow[t]{4}{*}{ De Martin et al. [47] } & 49 & & 5 years & $1 / 3 / 5$ years & $1 / 3 / 5$ years & \\
\hline & & $\mathrm{iCCC}^{\mathrm{a}}, \mathrm{HCC} / \mathrm{iCCC}^{\mathrm{b}} \leq 5 \mathrm{~cm}$ & 21 & $81 / 74 / 74$ & $\begin{array}{l}90 / 76 / 67 \\
1 / 3 / 5 \text { years }\end{array}$ & NS: ${ }^{a}$ versus ${ }^{b}$ \\
\hline & & $\leq 2 \mathrm{~cm}^{\mathrm{c}}$ & & & $92 / 87 / 69$ & NS: ${ }^{c}$ versus ${ }^{d}$ \\
\hline & & $>2, \leq 5^{\mathrm{d}}$ & & & $87 / 65 / 65$ & \\
\hline
\end{tabular}

Oncological Outcome Data

A 1-, 3-, and 5-year recurrence-free survival (RFS) of $60,22.5$, and $22.5 \%$, respectively, has been most recently described in only 10 patients by Krasnodębski et al. [45]. All of these patients underwent LT for PSC, while pCCC was found incidentally posttransplant, not detected in the preoperative findings due to a small tumor size of a median of $3 \mathrm{~cm}$ with $<5 \%$ positive lymph nodes. Similar good results were presented by Tan et al. [46] in PSC patients with pCCC with an OS of $89.8,75.9,75.9$, and $73.2 \%$, much better than the survival of de novo pCCC patients without PSC of 75.0, 58.0, 47.5, and $35.2 \%$ at 1 , 3,5 , and 10 years, respectively. This difference however vanished if residual tumor was present after LT and survival was comparable inferior in both groups (Table 2). De Martin et al. [47] have the same good results in a cohort of both, iCCC, or combined HCC/iCCC patients with a 1-, 3-, and 5-year OS and RFS of $81,74,74 \%$ and $90,76,67 \%$, respectively (Table 2). There was no difference in survival based on the type of tumor; however, tumor differentiation and the median diameter of the largest nodule were predictors for tumor recurrence and OS [47]. Wong et al. [48] have expanded the criteria for LT in pCCC with neoadjuvant therapy for downstaging. Eighteen patients met their center-specific criteria for this procedure with a success rate of $28 \%(n=5)$ who were finally eligible for LT. An OS of $80 \%(n=4 / 5)$ after 1 year is comparable to the other cohorts presented above; however, the RFS was only $75 \%(n=3 / 4)$ at that time, and a number of patients were too low to draw any further conclusions.

\section{Hepatic Epitheloid Hemangioendothelioma}

Radiological Findings

MRI of the liver is a highly accurate method for evaluating focal liver lesions as most of them do have specific MRI features. HEHE shows a moderate to markedly high signal on T2-weighted images. Also, peripheral ring enhancement on the late arterial phase has been reported. Some reports observed a targetoid appearance of the tumor on the later post-contrast phases [14]. Other imaging features are a "halo sign" (describes a ring-like enhancement during the arterial phase, with central filling in the delayed and portal phases) and a "lollipop sign" (describes portal vein entering and terminating the periphery of the lesion) on CT and MRI, which can help in diagnosis [21]. However, HEHE belongs to uncommon liver lesions with not always typical imaging features, and a biopsy for its diagnosis is therefore necessary. Outcome after LT in HEHE must be assessed further, as recurrence is an unpredictable event after LT [11] (Table 3).

\section{Radiological Predictors of Inferior Oncological}

Outcome

Currently, there are no studies on imaging features of HEHE that would influence the outcome after LT. HEHE is a rare tumor entity; however, the indication for LT even 
Table 3. Outcomes after LT for HEHE

\begin{tabular}{|c|c|c|c|c|c|}
\hline Author & Patients, $n$ & Criteria for $\mathrm{LT}$ & $\mathrm{RR}, \%$ & RFS, \% & OS rate, $\%$ \\
\hline Cao et al. [50] & 2 & Unresectable, diffuse extensive hepatic bilobar lesions & & $\begin{array}{l}15 / 52 \text { months } \\
100 / 100\end{array}$ & \\
\hline Brahmbhatt et al. [51] & 88 & Unresectable lesions & & & $\begin{array}{l}1 / 3 / 5 \text { years } \\
88.6 / 78.9 / 77.2\end{array}$ \\
\hline Rial et al. [53] & 2 & Unresectable bilobar lesions & & $\begin{array}{l}5 / 10 \text { years } \\
100 / 100\end{array}$ & \\
\hline Krasnodębski et al. [52] & 18 & Unresectable lesions & & $\begin{array}{l}65.9 \text { months } \\
100\end{array}$ & $\begin{array}{l}1 / 5 / 15 \text { years } \\
94 / 82.6 / 41.3\end{array}$ \\
\hline
\end{tabular}

LT, liver transplantation; HEHE, hepatic epitheloid hemangioendothelioma; RR, recurrence rate; RFS, recurrence-free survival; OS, overall survival.

Table 4. Outcomes after LT for hepatoblastoma

\begin{tabular}{|c|c|c|c|c|c|}
\hline Author & Patients, $n$ & Criteria for LT & $\mathrm{RR}, \%$ & RFS, \% & OS rate, $\%$ \\
\hline Herden et al. [57] & 7 & $\begin{array}{l}\text { PRETEXT III-IV, adjuvant } \\
\text { chemotherapy }\end{array}$ & $\begin{array}{l}\text { Median } 7.1 \text { years } \\
0\end{array}$ & $\begin{array}{l}\text { Median } 7.1 \text { years } \\
100\end{array}$ & $\begin{array}{l}\text { Median } 7.1 \text { years } \\
100\end{array}$ \\
\hline Okur et al. [91] & 10 & $\begin{array}{l}\text { PRETEXT III-IV, adjuvant } \\
\text { chemotherapy }\end{array}$ & & $\begin{array}{l}\text { Median } 32(9-69) \text { months } \\
80\end{array}$ & $\begin{array}{l}\text { Median } 32(9-69) \text { months } \\
80\end{array}$ \\
\hline Hendrickson et al. [92] & 6 & $\begin{array}{l}\text { PRETEXT II-IV, adjuvant } \\
\text { chemotherapy }\end{array}$ & $\begin{array}{l}\text { Average } 4 \\
(1.4-11.8) \text { years } \\
0\end{array}$ & $\begin{array}{l}\text { Average } 4(1.4-11.8) \text { years } \\
100\end{array}$ & $\begin{array}{l}\text { Average } 4(1.4-11.8) \text { years } \\
100\end{array}$ \\
\hline Kulkarni et al. [58] & 103 & $\begin{array}{l}\text { Unresectable tumors, perioperative } \\
\text { chemotherapy ( } 99 \% \text { of cases) }\end{array}$ & & & $\begin{array}{l}5 \text { years } \\
80.5\end{array}$ \\
\hline
\end{tabular}

LT, liver transplantation; RR, recurrence rate; RFS, recurrence-free survival; OS, overall survival; PRETEXT, Pretreatment Extent of Disease.

in advanced stage is given [49]. The current imaging criteria before and after transplantation should be considered $[41,44]$.

Oncological Outcome Data

The most recent literature describes an excellent RFS of up to $100 \%$ within 5 and 10 years [50-53]. No specific selection criteria were described in the largest cohort of 88 patients derived from the UNOS database [51]; however, it is common sense that LT is indicated in unresectable tumors as described in the other listed reports ( Table 3). Brahmbhatt et al. [51] have compared the OS with HCC, CCC, and NELM patients undergoing LT and clearly state that the outcome of HEHE is similar to that of HCC within Milan, while it is superior to both CCC and NELM.

\section{Hepatoblastoma}

\section{Radiological Findings}

Hepatoblastoma appears as a predominantly echogenic soft tissue mass in ultrasound (US). In larger tumors, heteroechogeneity is common, and also intralesional calcifications may be visible [9]. CT usually demonstrates a well-defined heterogeneous mass, usually hypoattenuating compared to the surrounding liver parenchyma. The areas of necrosis and hemorrhage could be seen, as well as dense calcifications [8].

\section{Radiological Predictors of Inferior Oncological \\ Outcome}

Predictors of inferior outcome include advanced Evans staging, disease involving both lobes, rupture, low AFP, and suboptimal response to first-line chemotherapy [54]. Imaging findings should include number, anatomical location and radiological tumor pattern, extrahepatic metastases, and vascular and biliary complications [55] since all of these factors have been reported to correlate with outcome [56]. In general, great attention should be paid to accurate pre- and especially posttransplant imaging to detect complications after LT, as these also have an impact on the outcome $[41,44]$.

\section{Oncological Outcome Data}

Very few patients have been reported over the last 2 years. The vast majority of patients underwent neoadjuvant chemotherapy for a Pretreatment Extent of Dis- 
Table 5. Outcomes after LT for colorectal liver metastases

\begin{tabular}{|c|c|c|c|c|c|}
\hline Author & Patients, $n$ & Criteria for LT & $\mathrm{RR}, \%$ & RFS & OS \\
\hline $\begin{array}{l}\text { Smedman } \\
\text { et al. [67] }\end{array}$ & 10 & $\begin{array}{l}\text { Synchronous unresectable CRLM, status post radical resection of the primary tumor, } \\
\text { chemotherapy, largest liber metastasis } \leq 10 \mathrm{~cm} \text {, weight loss } \leq 10 \% \text { in last } 6 \text { mo, } \mathrm{BMI} \leq 30 \text {; } \\
\text { resectable pulmonary metastases allowed (LT with extended criteria donor grafts) }\end{array}$ & $\begin{array}{l}\text { Median } 23 \\
\text { months } \\
80\end{array}$ & $\begin{array}{l}4 \text { months } \\
\text { (median) }\end{array}$ & $\begin{array}{l}18 \text { months } \\
\text { (median) }\end{array}$ \\
\hline
\end{tabular}

LT, liver transplantation; RR, recurrence rate; RFS, recurrence-free survival; OS, overall survival.

ease (PRETEXT) II-IV before LT (Table 4). The best reported RFS of up to 7.1 years after LT was 100\% [57] (Table 4). While both neoadjuvant and perioperative chemotherapy are of great benefit for survival after LT, adjuvant chemotherapy alone has not shown improved survival [58].

\section{Metastatic Neuroendocrine Tumors \\ Radiological Findings}

The appearance of NELM in US is variable with mixed hyper- and hypoechoic patterns. The central cystic appearance is highly characteristic of NELM in US. As most NELMs are hypervascular, they appear hyperattenuated on CT, but they can also appear hyperattenuated with washout, in dependence of whatever their origin is: pancreatic or enteric NET. Initial workup should include contrast-enhanced CT to evaluate the liver burden, but also extrahepatic disease. Also, to detect extrahepatic disease, metabolic imaging with ${ }^{68}$ Gallium-labeled somatostatin analogues ${ }^{68}$ Gallium-DOTA-Tyr3-octreotate $\left({ }^{68} \mathrm{Ga}\right.$-DOTATOC PET/CT) [59] should be performed. If the patient is considered for surgical resection, MRI of the liver with diffusion-weighted imaging using hepatospecific contrast medium is indicated. Postoperative followup imaging after LT ideally is performed with MRI; however, CT is often performed for the exclusion of post-LT complications. Metabolic imaging is useful in cases where morphological imaging indicates recurrence [13].

\section{Radiological Predictors of Inferior Oncological \\ Outcome}

Outcome after LT in NELM depends on the primary tumor. Several studies have shown that patients with a pancreatic NET had a worse 5-year survival compared with patients who had a gastrointestinal NET [60]. Therefore hepatomegaly, large liver metastases, Whipple's procedure or splenectomy, age of $>50$ years, and high tumor grade indicate inferior prognosis [60]. Thus, if necessary, a combination of all available imaging modalities for NET should be used to provide information of the above accordingly.

Oncological Outcome Data

Valvi et al. [61] have published data on 206 patients from the UNOS data set (1988-2018) with a 34\% RR and median time to recurrence of 28 months (range, 1-192 months). Indication for LT followed various standards and was not further specified in the article. The overall 1-, 3-, 5-, and 10-year patient survival rates were 89.1, 75.3, 64.9 , and $46.1 \%$, respectively. Patients $\leq 45$ years of age had significantly improved survival after LT for NELM, and a waiting time longer than 6 months was associated with lower RR. Korda et al. have analyzed their 10 center patients. The estimated 1- and 5-year RFS rates were 80 and $43 \%$, respectively. Every patient whose primary tumor was of pancreatic origin or those recipients who had Ki67 index values in the explanted liver $>5 \%$ have developed recurrent disease [62]. Ruzzenente et al. [63] analyzed a multi-institutional cohort of 28 patients including status post-resection of portal system-drained NET, patients with stable disease or response to therapies for $\geq 6$ months, $<50 \%$ tumor mass of total liver volume, lowgrade NET, and age $\leq 60$ years. Excellent OS of $83 \%$ was achieved in the cases within Milan. If G1, status post minor liver resection, only 1-2 liver metastases, or a small tumor size $(<3 \mathrm{~cm})$, the survival was even better in these within Milan patients and were 90, 92, 94, and 100\%, respectively.

\section{Colorectal Liver Metastases}

Radiological Findings

Typical findings in colorectal liver metastases on CT and MRI are well defined, solid, and on US hypoechoic lesions, sometimes with "target" or "bull's eye" appearance [64]. Gadoxetic acid-enhanced MRI of the liver is superior to $\mathrm{CT}$ in the detection of colorectal liver metastases up to $1 \mathrm{~cm}$ in diameter in patients with moderateto-severe fatty infiltration of the liver. A combination of MRI and intraoperative US may further improve the outcome of surgical treatment [65].

\section{Radiological Predictors of Inferior Oncological \\ Outcome}

The overall outcome after LT in colorectal metastases is poor. There are no specific radiological predictors of oncological outcome available; however, as in most tumor entities, tumor size and vascular invasion cT4 potentially decrease a benefit of LT $[26,41]$. Indeed, according to the SECA-I trial, a tumor diameter of $>5.5$ 
Table 6. Outcomes after LT for neuroendocrine liver metastases

\begin{tabular}{lcclcc}
\hline Author & Patients, $n$ & Criteria for LT & RR, $\%$ & RFS, \% & OS rate, $\%$ \\
\hline Korda et al. [62] & 10 & Not specified & $\begin{array}{l}\text { Median 33 months } \\
50\end{array}$ & $\begin{array}{l}1 / 5 \text { years } \\
80 / 43\end{array}$ & $\begin{array}{l}1 / 5 \text { years } \\
89 / 71\end{array}$ \\
\hline Ruzzenente et al. [63] & 28 & Milan criteria & & 5 years \\
& & & & 83 \\
\hline Valvi et al. [61] & 206 & Not specified & Median 28 (1-192) months & $1 / 3 / 5 / 10$ years \\
& & & 34 & $89.1 / 75.3 / 64.9 / 46.1$ \\
\hline
\end{tabular}

LT, liver transplantation; RR, recurrence rate; RFS, recurrence-free survival; OS, overall survival.

$\mathrm{cm}$ is an independent factor for inferior outcome and progressive disease after neoadjuvant chemotherapy [66].

\section{Oncological Outcome Data}

Most recently, the data on 10 patients of the SECA-II arm D study were published [67]. Patients included were not eligible for inclusion in the arms $\mathrm{A}, \mathrm{B}$, and $\mathrm{C}$ of the SECA-II study [67] (Table 5). Even patients who had resectable pulmonary metastases were eligible for inclusion. Patients had an extended tumor load including N2; however, liver metastases $>10 \mathrm{~cm}$ were excluded. Almost all the patients underwent LT with extended criteria donor grafts. Both OS and disease-free survival were poor with a median of 18 and 4 months, respectively. This small cohort with short OS clearly shows the limits in LT for colorectal liver metastases (Table 5).

To date, results of the still ongoing trials (SECA-III, RAPID, LIVERT(W)OHEosAL, TRANSMET, COLT, TRIPLETE, and SOULMATE) are still pending.

\section{Discussion/Conclusion}

\section{General Remarks}

This article combines the most recent published oncological outcome data after LT for malignancies together with pretransplant imaging describing typical findings for the various tumor entities.

Since modern imaging technology has led to an increased sensitivity and specificity, earlier tumor stages are detected. If this technology is combined with scores like the Milan criteria that were implemented decades ago, it is obvious that LT for HCC today is restricted to much earlier stages than the past. Further, early tumor stages can be better diagnosed with the current modern imaging modalities, that is, hepatospecific contrast media, which allows the detection even of very small liver lesions of up to a diameter of $<1 \mathrm{~cm}$ [68]. Thus, criteria that are much more expanded than Milan have led to ac- ceptable oncological outcomes [69]. This is of special importance in these complex LT candidates since all of the cases are discussed in multidisciplinary tumor boards and/or transplant boards. During the discussion considering LT, the impact of imaging results plays a crucial role.

Further, the excellent tumor-free survival is achieved today with novel multimodal treatment concepts and is directly linked with both high-tech imaging and the application of well-established and novel prognostic scores and parameters.

Indeed, this article does not aim to newly define indications for LT in malignancies but clearly underlines the need of a tailored, sometimes even multimodal approach in every patient using modern imaging modalities, novel (neo-)adjuvant chemotherapy, and innovative immunosuppressive regimens to obtain best possible outcomes in both quality of life and life years gained. Guidelines [70, 71] shall be considered and also be constantly re-evaluated based on the newest literature. LT can be performed outside the framework of the most actual and exclusively medical-based guidelines; however, if done so, there is a need for justification given organ shortage, which is the predominant challenge of LT. While under the line LT may be at least the best palliation for most patients with malignant liver tumors, this approach is limited by organ shortage and the associated commitment to gain as many life years as possible per transplanted organ.

How is the oncological outcome after LT for the malignancies that are considered transplant indications today?

\section{Hepatocellular Carcinoma}

HCC is the ninth most common malignancy among women worldwide and is the fifth most common malignancy in men [72]. HCC within the setting of cirrhosis is given a higher priority, and thus, it is a rapidly growing indication for LT [11]. Both the detection and treatment of HCC have evolved significantly during the last decade and comprise local ablation, chemoembolization, and 
laparoscopic liver resection toward transplantation [73] and promising trials on adjuvant chemotherapy [74] after LT for a curative intention. Early-stage HCCs [75] without vascular invasion or metastasis are considered best candidates for LT. However, patients within the conservative Milan criteria who undergo local tumor control used not only for downstaging but also as predictor for oncological outcome [76] are critically evaluated before LT and thus have an excellent outcome [77]. Most recent data published show a 5-year OS of 82.5\% [15] (Table 1) comparable to the expected survival of patients who do not have HCC. Most importantly with the modern diagnostic imaging and perioperative management even in patients with expanded Milan criteria, that is, the Hangzhou criteria [38], 5-5-500 rule [19], UCFS [17], AFP model [16], TTV-AFP model (for beyond Milan patients) [16], Kyoto criteria [16], and UT7 criteria [15], an acceptable outcome is obtained (Table 1). Further, the MoRAL score is an excellent predictor for HCC recurrence after LT [16] (Table 1). Moreover, novel scores, such as the 5-5-500 which includes the AFP value and the ORS [15] which includes AFP as well as additional predictors like CRP [17] and the ALBI score, combine relevant factors in tumor biology to allow a better patient selection (Table 1).

However, it seems that most established or newly developed scores and models more or less lead to similar outcomes. Thus, the full management of patients in the various centers shall be compared to make underlying prerequisites transparent for better comparison of the investigated scores and models.

\section{Cholangiocellular Carcinoma}

CCC is the most common biliary and the second most common primary hepatic malignancy [78] and is classified for LT in iCCC and pCCC. While patients with iCCC are not classical candidates for LT, LT would be the treatment of choice in patients with pCCC, especially using the Mayo protocol combining aggressive high-dose neoadjuvant chemoradiotherapy before staging, but also selecting and operatively staging patients prior to LT [79]. In the past, Mantel et al. [80] reported 147 patients with a 5 -year OS of 59\%. The data from 12 US centers demonstrated a 5 -year RFS of $65 \%$ of the liver-transplanted patients with pCCC [23]. Most recent studies have shown that LT is justified for patients with unresectable very early iCCC and combined HCC/iCCC, with survival outcomes comparable to those of HCC (62) (Table 2). Best results however are clearly obtained in patients who underwent LT for PSC with incidentally found pCCC, while comparable results can be obtained in PSC patients with pCCC diagnosed before LT $[45,46]$ (Table 2). Further, there appears no difference in outcome if patients with small
iCCC and combined HCC/iCCC undergo LT [47] (Table 2). However, in these patients, both median size and type of the tumor are predictors for survival. Even downstaging can successfully lead patients toward LT with curative intention [48]. The role of LT in CCC remains to be elucidated by ongoing clinical trials.

\section{Hepatic Epitheloid Hemangioendothelioma}

Malignant HEHE is a rare vascular neoplasm of unknown etiology. A 5 -year OS of $54.5 \%$ was reported in a review of published series [81]. In the large ELTR-ELITA series, OS was 77 and $74 \%$ after 5 and 10 years, respectively [82]. Tumor recurrence was associated with lymph node metastases, macrovascular invasion, and a waiting time of $>120$ days. Data from the UNOS database have shown an OS and RFS of 70 and $55 \%$ at 5 years, respectively [83]. The most recent data published go in line with the previous findings (Table 3 ). With an OS of $77.2 \%$ in 88 reviewed patients [51], there was even $100 \%$ RFS at 5 and 10 years in a small case series [53]. Under the line, the best criteria for patient selection and management are still under debate and thus need to be addressed further.

\section{Hepatoblastoma}

Hepatoblastoma is a malignant pediatric tumor. Most recently, 3 small case series have been published with a total number of 42 patients all with excellent OS and RFS (Table 4) of up to $100 \%$ at 7.1 years [57]. A most recent published analysis of the US National Cancer Database (NCDB) including a total number of 103 children who underwent LT for hepatoblastoma with a 5-year OS of $80 \%$ revealed an inferior outcome at older ages at LT and has demonstrated the great benefit of neoadjuvant or perioperative chemotherapy, while adjuvant chemotherapy alone has no benefit [58].

\section{Neuroendocrine Liver Metastasis}

NELMs are common and currently the only metastases with indication for LT outside from clinical trials. While the selection criteria are controversial, Mazzaferro et al. [84] and UNOS [85] defined similar criteria which led to an OS of 73\% [60]. This means that patients who meet the selection criteria can be cured with LT. Patients with NELM should therefore be introduced to a highly specialized transplant center and be evaluated for LT [86]. Most recent publications (Table 6) confirm the commonly used selection criteria with a reported 5-year OS of 83 [63], 71 [62], and 64.9\% [61]. Both pancreatic NELM and NELM with a Ki67 > 5\% [62] and patients $\leq 45$ years of age or waiting for $\mathrm{LT}<6$ months have a higher RR [61]. Further G1 and a low number or small size $(<3 \mathrm{~cm})$ of NELM are beneficial for a 5-year survival of 92,100 , and $100 \%$, respectively [63]. 


\section{Colorectal Metastases}

Colorectal cancer is one of the most common cancers worldwide. Approximately $20-25 \%$ of patients with colorectal cancer present with simultaneous liver metastases. Unfortunately, only $30-40 \%$ of the patients are the candidates for radical liver resection at the time of diagnosis, and thus, LT would be a curative option [87]. Initial reports on the outcome after LT in these patients showed poor results [88]. Further, most recent publication of patients who underwent LT with a large tumor load has confirmed a disastrous outcome [67] (Table 5). It was not before 2013 with the published 21 patients included in the SECA-I study [66] when LT was recognized as a therapeutic option in patients with colorectal liver metastases. OS was $95 \%$ at 1 year and $60 \%$ at 5 years [89]. This trial revealed independent factors for inferior outcome: tumor diameter of $>5.5$ $\mathrm{cm}$, time from primary tumor resection $<2$ years, carcinoembryonic antigen levels $>80 \mu \mathrm{g} / \mathrm{L}$, and progressive disease after neoadjuvant chemotherapy. In the SECA-II trial, it became clear that especially a minimal response to chemotherapy of $10 \%$ is needed for 100,83 , and $83 \%$ after 1,3 , and 5 years, respectively [90]. The most recently published SECA-II arm D study clearly shows the limits of LT in patients with a huge tumor load in the liver, GIII metastases, with or without N2-positive lymph nodes at transplantation or previously resected lung metastases [67].
Hopefully, the ongoing stricter selecting trials (SECAIII, RAPID, LIVERT(W)OHEosAL, TRANSMET, COLT, TRIPLETE, and SOULMATE) will confirm this treatment concept.

\section{Statement of Ethics}

The authors have no ethical conflicts to disclose. The article is exempt from ethical committee approval, and written patient consent was not necessary because it was based on a review of already published literature.

\section{Conflict of Interest Statement}

The authors have no conflicts of interest to declare.

\section{Funding Sources}

The authors have no funding sources to declare.

\section{Author Contributions}

Both E.T. (Emina Talakić) and P.S. (Peter Schemmer) were responsible for the study concept and design and wrote the manuscript. E.J. (Elmar Janek) and S.M. (Saulius Mikalauskas) were responsible for the literature review. E.J. and S.M. critically revised the drafted manuscript. All authors have read and agreed to the final version of the manuscript.

\section{References}

1 Starzl TE, Marchioro TL, Vonkaulla KN, Hermann G, Brittain RS, Waddell WR. Homotransplantation of the liver in humans. Surg Gynecol Obstet. 1963 Dec;117:659-76.

2 Starzl TE, Groth CG, Brettschneider L, Penn I, Fulginiti VA, Moon JB, et al. Orthotopic homotransplantation of the human liver. Ann Surg. 1968 Sep;168(3):392-415.

3 European Association for the Study of the Liver. EASL clinical practice guidelines: liver transplantation. J Hepatol. 2016 Feb;64(2):433-85.

4 European Liver Transplant Registry. 2020 Oct 1. p. Self-deception. Retrieved from: www.eltr.org.

5 Adam R, Karam V, Cailliez V, Grady JGO, Mirza D, Cherqui D, et al. 2018 annual report of the European liver transplant registry (ELTR): 50year evolution of liver transplantation. Transpl Int. 2018 Dec;31(12):1293-317.

6 Tasdogan BE, Ma M, Simsek C, Saberi B, Gurakar A. Update on immunosuppression in liver transplantation. Euroasian J Hepatogastroenterol. 2019 Jul-Dec;9(2):96-101.

7 Mitra AK, Agrahari V, Mandal A, Cholkar K, Natarajan C, Shah S, et al. Novel delivery approaches for cancer therapeutics. J Control Release. 2015 Dec 10;219:248-68.

8 King SJ, Babyn PS, Greenberg ML, Phillips MJ, Filler RM. Value of CT in determining the resectability of hepatoblastoma before and after chemotherapy. AJR Am J Roentgenol. 1993 Apr;160(4):793-8.

9 Gubernick JA, Rosenberg HK, Ilaslan H, Kessler A. US approach to jaundice in infants and children. Radiographics. 2000 Jan-Feb; 20(1):173-95.

10 Kim SA, Lee JM, Lee KB, Kim SH, Yoon SH, Han JK, et al. Intrahepatic mass-forming cholangiocarcinomas: enhancement patterns at multiphasic CT, with special emphasis on arterial enhancement pattern--correlation with clinicopathologic findings. Radiology. 2011 Jul;260(1):148-57.

11 Abdoh QA, Alnajjar AM, Abaalkhail FA, Al Sebayel M, Al-Hussaini HF, Al-Hamoudi WK, et al. Aggressive recurrence of primary hepatic epithelioid haemangioendothelioma after liver transplantation. Can J Gastroenterol Hepatol. 2016;2016:6135297.

12 Joo I, Lee JM, Yoon JH. Imaging diagnosis of intrahepatic and perihilar cholangiocarcinoma: recent advances and challenges. Radiology. 2018 Jul;288(1):7-13.

13 Ronot M, Clift AK, Baum RP, Singh A, Kulkarni HR, Frilling A, et al. Morphological and functional imaging for detecting and assessing the resectability of neuroendocrine liver metastases. Neuroendocrinology. 2018;106(1): 74-88.

14 Semelka RC, Nimojan N, Chandana S, Ramalho M, Palmer SL, DeMulder D, et al. MRI features of primary rare malignancies of the liver: a report from four university centres. Eur Radiol. 2018 Apr;28(4):152939.

15 Kornberg A, Witt U, Schernhammer M, Kornberg J, Müller K, Friess H, et al. The role of preoperative albumin-bilirubin grade for oncological risk stratification in liver transplant patients with hepatocellular carcinoma. J Surg Oncol. 2019 Dec; 120(7):1126-36.

16 Mehta N, Yao FY. What are the optimal liver transplantation criteria for hepatocellular carcinoma? Clin Liver Dis. 2019 Jan;13(1):20-5.

17 Meischl T, Rasoul-Rockenschaub S, Györi G Sieghart W, Reiberger T, Trauner M, et al. Creactive protein is an independent predictor for hepatocellular carcinoma recurrence after liver transplantation. PLoS One. 2019;14(5): e0216677.

18 Ronot M, Purcell Y, Vilgrain V. Hepatocellular carcinoma: current imaging modalities for diagnosis and prognosis. Dig Dis Sci. 2019 Apr;64(4):934-50.

19 Shimamura T, Akamatsu N, Fujiyoshi M, Kawaguchi A, Morita S, Kawasaki S, et al. Expanded living-donor liver transplantation criteria for patients with hepatocellular carcinoma based on the Japanese nationwide survey: the 5-5-500 rule: a retrospective study. Transpl Int. 2019 Apr;32(4):356-68.

20 Vutien P, Dodge J, Bambha KM, Nordstrom EM, Gralla J, Campbell K, et al. A simple measure of hepatocellular carcinoma burden predicts tumor recurrence after liver transplantation: the recurrent hepatocellular carcinoma-initial, maximum, last classification. Liver Transplant. 2019 Apr;25(4): 559-70. 
21 Virarkar M, Saleh M, Diab R, Taggart M, Bhargava P, Bhosale P. Hepatic hemangioendothelioma: an update. World J Gastrointest Oncol. 2020 Mar 15;12(3):248-66.

22 Lee WM, Stravitz RT, Larson AM. Introduction to the revised American association for the study of liver diseases position paper on acute liver failure 2011. Hepatology. 2012 Mar;55(3):965-7.

23 Darwish Murad S, Kim WR, Harnois DM, Douglas DD, Burton J, Kulik LM, et al. Efficacy of neoadjuvant chemoradiation, followed by liver transplantation, for perihilar cholangiocarcinoma at 12 US centers. Gastroenterology. 2012 Jul;143(1):88-98.e3; quiz e14.

24 Hibi T, Sapisochin G. What is transplant oncology? Surgery. 2019 Feb;165(2):281-5.

25 Abreu P, Gorgen A, Oldani G, Hibi T, Sapisochin G. Recent advances in liver transplantation for cancer: the future of transplant oncology. JHEP Rep. 2019 Nov; 1(5):377-91.

26 Girometti R, Pancot M, Como G, Zuiani C. Imaging of liver transplantation. Eur J Radiol. 2017 Aug;93:295-307.

27 Poullos PD, Tseng JJ, Melcher ML, Concepcion W, Loening AM, Rosenberg J, et al. Structured reporting of multiphasic CT for hepatocellular carcinoma: effect on staging and suitability for transplant. AJR Am J Roentgenol. 2018 Apr;210(4):766-74.

28 Mazzaferro V, Regalia E, Doci R, Andreola S, Pulvirenti A, Bozzetti F, et al. Liver transplantation for the treatment of small hepatocellular carcinomas in patients with cirrhosis. N Engl J Med. 1996 Mar 14;334(11):693-9.

29 Yao FY, Xiao L, Bass NM, Kerlan R, Ascher NL, Roberts JP. Liver transplantation for hepatocellular carcinoma: validation of the UCSF-expanded criteria based on preoperative imaging. Am J Transplant. 2007 Nov;7(11): 2587-96.

30 Clavien PA, Lesurtel M, Bossuyt PM, Gores GJ, Langer B, Perrier A. Recommendations for liver transplantation for hepatocellular carcinoma: an international consensus conference report. Lancet Oncol. 2012 Jan;13(1): e11-22.

31 Yao FY. Liver transplantation for hepatocellular carcinoma: beyond the Milan criteria. Am J Transplant. 2008 Oct;8(10):1982-9.

32 Mazzaferro V, Sposito C, Zhou J, Pinna AD, De Carlis L, Fan J, et al. Metroticket 2.0 model for analysis of competing risks of death after liver transplantation for hepatocellular carcinoma. Gastroenterology. 2018 Jan;154(1): 128-39.

33 Otto G, Herber S, Heise M, Lohse AW, Mönch $\mathrm{C}$, Bittinger F, et al. Response to transarterial chemoembolization as a biological selection criterion for liver transplantation in hepatocellular carcinoma. Liver Transplant. 2006 Aug;12(8):1260-7.

34 Roayaie S, Schwartz JD, Sung MW, Emre SH Miller CM, Gondolesi GE, et al. Recurrence of hepatocellular carcinoma after liver transplant: patterns and prognosis. Liver Transplant. 2004 Apr;10(4):534-40.

35 Ghabril M, Agarwal S, Lacerda M, Chalasani N, Kwo P, Tector AJ. Portal vein thrombosis is a risk factor for poor early outcomes after liver transplantation: analysis of risk factors and outcomes for portal vein thrombosis in waitlisted patients. Transplantation. 2016 Jan; 100(1):126-33.

36 Feng J, Zhu R, Feng D, Yu L, Zhao D, Wu J, et al. Prediction of early recurrence of solitary hepatocellular carcinoma after orthotopic liver transplantation. Sci Rep. 2019 Nov 1;9(1): 15855.

37 Dioguardi Burgio M, Ronot M, Fuks D, Dondero F, Cauchy F, Gaujoux S, et al. Follow-up imaging after liver transplantation should take into consideration primary hepatocellular carcinoma characteristics. Transplantation. 2015 Aug;99(8):1613-8.

38 Al-Ameri AAM, Wei X, Liu P, Lin L, Shao Z, Xie $\mathrm{H}$, et al. Prediction of early recurrence of hepatocellular carcinoma in patients with cirrhosis who had received deceased donor liver transplantation: a multicenter study. Ann Transplant. 2019 Aug 20;24:489-98.

39 Ho SY, Hsu CY, Liu PH, Hsia CY, Su CW, Huang $\mathrm{YH}$, et al. Albumin-bilirubin (ALBI) grade-based nomogram to predict tumor recurrence in patients with hepatocellular carcinoma. Eur J Surg Oncol. 2019 May;45(5):776-81.

40 Sammon J, Fischer S, Menezes R, HosseiniNik H, Lewis S, Taouli B, et al. MRI features of combined hepatocellular- cholangiocarcinoma versus mass forming intrahepatic cholangiocarcinoma. Cancer Imaging. 2018 Feb 27;18(1):8.

41 Singh AK, Cronin CG, Verma HA, Boland GW, Saini S, Mueller PR, et al. Imaging of preoperative liver transplantation in adults: what radiologists should know. Radiographics. 2011 Jul-Aug;31(4):1017-30.

42 Zhang $\mathrm{H}$, Zhu J, Ke F, Weng M, Wu X, Li M, et al. Radiological imaging for assessing the respectability of hilar cholangiocarcinoma: a systematic review and meta-analysis. Biomed Res Int. 2015;2015:497942.

43 Salvolini L, Urbinati C, Valeri G, Ferrara C, Giovagnoni A. Contrast-enhanced MR cholangiography (MRCP) with GD-EOB-DTPA in evaluating biliary complications after surgery. Radiol Med. 2012 Apr;117(3):354-68.

44 Girometti R, Como G, Bazzocchi M, Zuiani C. Post-operative imaging in liver transplantation: state-of-the-art and future perspectives. World J Gastroenterol. 2014 May 28;20(20): 6180-200.

45 Krasnodębski M, Grąt M, Wierzchowski M, Szczęśniak M, Morawski M, Zając K, et al. Analysis of patients with incidental perihilar cholangiocarcinoma: an old and a persistent burden for liver transplantation. Transplant Proc. 2020 Oct;52(8):2507-11.

46 Tan EK, Rosen CB, Heimbach JK, Gores GJ, Zamora-Valdes D, Taner T. Living donor liver transplantation for perihilar cholangiocarcinoma: outcomes and complications. J Am Coll Surg. 2020 Jul;231(1):98-110.

47 De Martin E, Rayar M, Golse N, Dupeux M, Gelli M, Gnemmi V, et al. Analysis of liver resection versus liver transplantation on outcome of small intrahepatic cholangiocarcinoma and combined hepatocellular-cholangiocarcinoma in the setting of cirrhosis. Liver Transplant. 2020 Jun;26(6):785-98.

48 Wong M, Kim J, George B, Eriksen C, Pearson $\mathrm{T}$, Robbins J, et al. Downstaging locally advanced cholangiocarcinoma pre-liver trans- plantation: a prospective pilot study. J Surg Res. 2019 Oct;242:23-30.

49 Lyburn ID, Torreggiani WC, Harris AC, Zwirewich CV, Buckley AR, Davis JE, et al. Hepatic epithelioid hemangioendothelioma: sonographic, CT, and MR imaging appearances. AJR Am J Roentgenol. 2003 May; 180(5):1359-64.

50 Cao L, Hong J, Zhou L, Ye Y, Liu Y, Yu J, et al. Selection of treatment for hepatic epithelioid hemangioendothelioma: a single-center experience. World J Surg Oncol. 2019 Nov 7; 17(1):183.

51 Brahmbhatt M, Prenner S, Bittermann T. Liver transplantation for hepatic epithelioid hemangioendothelioma is facilitated by exception points with acceptable long-term outcomes. Transplantation. 2020 Jun;104(6):1187-92.

52 Krasnodębski M, Grąt M, Morawski M, Wierzchowski M, Jastrzębski M, Remiszewski P, et al. Hepatic epithelioid hemangioendothelioma: a rare disease with favorable outcomes after liver transplantation. Transplant Proc. 2020 Oct;52(8):2447-9.

53 Rial X, López-Monclús J, Lucena JL, Chaparro MD, Pueyo A, Giménez Alvira L, et al. Hepatic epithelioid hemangioendothelioma as a rare indication for liver transplantation. Transplant Proc. 2020 Jun;52(5):1453-4.

54 Liu APY, Ip JJK, Leung AWK, Luk CW, Li $\mathrm{CH}, \mathrm{Ho} \mathrm{KKH}$, et al. Treatment outcome and pattern of failure in hepatoblastoma treated with a consensus protocol in Hong Kong. Pediatr Blood Cancer. 2019 Jan;66(1):e27482.

55 Shelmerdine SC, Roebuck DJ, Towbin AJ, McHugh K. MRI of paediatric liver tumours: how we review and report. Cancer Imaging. 2016 Aug 15;16(1):21.

56 Aronson DC, Schnater JM, Staalman CR, Weverling GJ, Plaschkes J, Perilongo G, et al. Predictive value of the pretreatment extent of disease system in hepatoblastoma: results from the International Society of Pediatric Oncology Liver Tumor Study Group SIOPEL-1 study. J Clin Oncol. 2005 Feb 20;23(6):1245-52.

57 Herden U, Grabhorn E, Lenhartz H, Kütemeier R, Fischer L. Excellent outcome following liver transplantation for hepatoblastoma using an extensive en bloc hepatectomy technique. Transplant Proc. 2019 Jul-Aug;51(6):1887-91.

58 Kulkarni S, Brauer DG, Turmelle Y, Stoll J, Nadler M, Chapman WC, et al. Surgical therapy for pediatric hepatoblastoma in the USA over the last decade: analysis of the national cancer database. J Gastrointest Cancer. 2020 May 27.

59 Sanli Y, Garg I, Kandathil A, Kendi T, Zanetti MJB, Kuyumcu S, et al. Neuroendocrine tumor diagnosis and management: (68)GaDOTATATE PET/CT. AJR Am J Roentgenol. 2018 Aug;211(2):267-77.

60 Le Treut YP, Grégoire E, Klempnauer J, Belghiti J, Jouve E, Lerut J, et al. Liver transplantation for neuroendocrine tumors in Europeresults and trends in patient selection: a 213 case European liver transplant registry study. Ann Surg. 2013 May;257(5):807-15.

61 Valvi D, Mei X, Gupta M, Shah MB, Ancheta A, Marti F, et al. Younger age is associated with improved survival in patients undergoing liver transplantation alone for metastatic neuroendocrine tumors. J Gastrointest Surg. 2020 Jul 6. 
62 Korda D, Doros A, Piros L, Gerlei Z, HaboubSandil A, Mándli T, et al. Liver transplant for metastatic neuroendocrine tumors: a singlecenter experience in Hungary. Transplant Proc. 2019 May;51(4):1251-3.

63 Ruzzenente A, Bagante F, Bertuzzo F, Aldrighetti L, Campagnaro T, Ercolani G, et al. Liver resection for neuroendocrine tumor liver metastases within Milan criteria for liver transplantation. J Gastrointest Surg. 2019 Jan; 23(1):93-100.

64 Tirumani SH, Kim KW, Nishino M, Howard SA, Krajewski KM, Jagannathan JP, et al. Update on the role of imaging in management of metastatic colorectal cancer. Radiographics. 2014 Nov-Dec;34(7):1908-28.

65 Berger-Kulemann V, Schima W, Baroud S, Koelblinger C, Kaczirek K, Gruenberger T, et al. Gadoxetic acid-enhanced 3.0 T MR imaging versus multidetector-row $\mathrm{CT}$ in the detection of colorectal metastases in fatty liver using intraoperative ultrasound and histopathology as a standard of reference. Eur J Surg Oncol. 2012 Aug;38(8): 670-6.

66 Hagness M, Foss A, Line PD, Scholz T, Jørgensen PF, Fosby B, et al. Liver transplantation for nonresectable liver metastases from colorectal cancer. Ann Surg. 2013 May; 257(5):800-6

67 Smedman TM, Line PD, Hagness M, Syversveen T, Grut H, Dueland S. Liver transplantation for unresectable colorectal liver metastases in patients and donors with extended criteria (SECA-II arm D study). BJS Open. 2020 Jun;4(3):467-77.

68 Ringe KI, Husarik DB, Sirlin CB, Merkle EM Gadoxetate disodium-enhanced MRI of the liver: part 1, protocol optimization and lesion appearance in the noncirrhotic liver. AJR Am J Roentgenol. 2010 Jul;195(1):13-28.

69 Yao FY, Ferrell L, Bass NM, Watson JJ, Bacchetti P, Venook A, et al. Liver transplantation for hepatocellular carcinoma: expansion of the tumor size limits does not adversely impact survival. Hepatology. 2001 Jun;33(6): 1394-403.

70 Available from: https://easl.eu.

71 Available from: https://www.aasld.org

72 Venook AP, Papandreou C, Furuse J, de Guevara LL. The incidence and epidemiology of hepatocellular carcinoma: a global and regional perspective. Oncologist. 2010;15(Suppl 4):5-13.
73 Daher S, Massarwa M, Benson AA, Khoury T. Current and future treatment of hepatocellular carcinoma: an updated comprehensive review. J Clin Transl Hepatol. 2018 Mar 28;6(1): 69-78.

74 Zhu XD, Li KS, Sun HC. Adjuvant therapies after curative treatments for hepatocellular carcinoma: current status and prospects. Genes Dis. 2020 Sep;7(3):359-69.

75 Clavien PA, Oberkofler CE, Raptis DA, Lehmann K, Rickenbacher A, El-Badry AM. What is critical for liver surgery and partial liver transplantation: size or quality? Hepatology. 2010 Aug;52(2):715-29.

76 Pompili M, Francica G, Ponziani FR, Iezzi R, Avolio AW. Bridging and downstaging treatments for hepatocellular carcinoma in patients on the waiting list for liver transplantation. World J Gastroenterol. 2013 Nov 21; 19(43):7515-30.

77 Yao FY, Mehta N, Flemming J, Dodge J, Hameed B, Fix O, et al. Downstaging of hepatocellular cancer before liver transplant: longterm outcome compared to tumors within Milan criteria. Hepatology. 2015 Jun;61(6): 1968-77.

78 Khan SA, Thomas HC, Davidson BR, TaylorRobinson SD. Cholangiocarcinoma. Lancet. 2005 Oct 8;366(9493):1303-14.

79 Duignan S, Maguire D, Ravichand CS, Geoghegan J, Hoti E, Fennelly D, et al. Neoadjuvant chemoradiotherapy followed by liver transplantation for unresectable cholangiocarcinoma: a single-centre national experience. HPB. 2014 Jan;16(1):91-8.

80 Mantel HT, Westerkamp AC, Adam R, Bennet WF, Seehofer D, Settmacher U, et al. Strict selection alone of patients undergoing liver transplantation for hilar cholangiocarcinoma is associated with improved survival. PLoS One. 2016;11(6):e0156127.

81 Mehrabi A, Kashfi A, Fonouni H, Schemmer P, Schmied BM, Hallscheidt P, et al. Primary malignant hepatic epithelioid hemangioendothelioma: a comprehensive review of the literature with emphasis on the surgical therapy. Cancer. 2006 Nov 1;107(9):2108-21.

82 Lai Q, Feys E, Karam V, Adam R, Klempnauer J, Oliverius M, et al. Hepatic epithelioid hemangioendothelioma and adult liver transplantation: proposal for a prognostic score based on the analysis of the ELTR-ELITA registry. Transplantation. 2017 Mar;101(3):55564.
83 Rodriguez JA, Becker NS, O'Mahony CA, Goss JA, Aloia TA. Long-term outcomes following liver transplantation for hepatic hemangioendothelioma: the UNOS experience from 1987 to 2005. J Gastrointest Surg. 2008 Jan;12(1):110-6.

84 Mazzaferro V, Pulvirenti A, Coppa J. Neuroendocrine tumors metastatic to the liver: how to select patients for liver transplantation? J Hepatol. 2007 Oct;47(4):460-6.

85 Orditura M, Petrillo A, Ventriglia J, Diana A, Laterza MM, Fabozzi A, et al. Pancreatic neuroendocrine tumors: nosography, management and treatment. Int J Surg. 2016 Apr; 28(Suppl 1):S156-62.

86 Kniepeiss D, Schemmer P. Transplantation bei lebermetastasen neuroendokriner tumoren: heilung oder palliation? J Klin Endokrinol Stoffw. 2020 Jun 1;13(2):54-8.

87 Manfredi S, Lepage C, Hatem C, Coatmeur O, Faivre J, Bouvier AM. Epidemiology and management of liver metastases from colorectal cancer. Ann Surg. 2006 Aug;244(2):254-9.

88 Mühlbacher F, Huk I, Steininger R, Gnant M, Götzinger P, Wamser P, et al. Is orthotopic liver transplantation a feasible treatment for secondary cancer of the liver? Transplant Proc. 1991 Feb;23(1 Pt 2):1567-8.

89 Hagness M, Foss A, Egge TS, Dueland S. Patterns of recurrence after liver transplantation for nonresectable liver metastases from colorectal cancer. Ann Surg Oncol. 2014 Apr; 21(4):1323-9.

90 Dueland S, Syversveen T, Solheim JM, Solberg S, Grut H, Bjørnbeth BA, et al. Survival following liver transplantation for patients with nonresectable liver-only colorectal metastases. Ann Surg. 2020 Feb;271(2):212-8.

91 Okur MH, Yankol Y, Cimşit B, Mecit N, Ertuğrul G, Kanmaz T, et al. Liver transplant in children with hepatoblastoma. Exp Clin Transplant. 2019 Oct;17(5):644-7.

92 Hendrickson RJ, Sujka J, Fischer R, Manalang M, Daniel J, Andrews WS. Indications and efficacy of conversion from tacrolimus- to sirolimus-based immunosuppression in pediatric patients who underwent liver transplantation for unresectable hepatoblastoma. Pediatr Transplant. 2019 May;23(3):e13369. 